\title{
IMPLANTAÇÃO DE ANALISADORES DE UMIDADE ON LINE NO VIRADOR DE VAGÕES EM PDM*
}

\section{Resumo}

\author{
Samara Sâmid Aguiar Correia ${ }^{1}$ \\ Lucia de Fátima Araujo Ferreira² \\ Pablo Jordano Sacramento Mendes ${ }^{3}$ \\ Rita Virgínia Gabriel da Silva
}

A crescente necessidade por resultados de análises laboratoriais dentro das indústrias são cada vez mais exigentes em termos de tempo de resposta e precisão. Aliado a isso, a elevação do volume de minério de ferro exportado e o aumento da variabilidade desses produtos requerem processos cada vez mais rigorosos e tomados de decisões mais rápidas. Nesse contexto, os analisadores on-line têm um papel fundamental, pois atendem tais exigências, além de preservarem a segurança operacional. Este trabalho tem por objetivo mostrar o desenvolvimento da implantação de analisadores de umidade on line na descarga dos vagões da Vale no Terminal Ponta da Madeira. A metodologia utilizada na medição de umidade dos analisadores usa o princípio de transmissão de micro-ondas, que é a melhor tecnologia disponível no mercado para este fim. Dentre as etapas de implantação, que abrange desde a aquisição dos equipamentos até a avaliação dos controles e ajustes operacionais, é mostrado o período de cada etapa, os problemas encontrados e as soluções adotadas. Em suma, atualmente há medição de umidade on line na descarga deste site e está em fase de implantação a análise durante o carregamento do embarque para controle de processo.

Palavras-chave: Analisadores on line; Umidade; Medição.

\section{IMPLEMENTATION OF MOISTURE ANALYZERS ON LINE ON CAR DUMPER IN PDM}

\section{Abstract}

The growing need for results of laboratory tests within industries is increasingly demanding in terms of response time and accuracy. In addition to that, the increase in the volume of iron ore exported and increased variability of these products require increasingly rigorous processes and faster decisions taken. In this context, on-line analyzers have an essential role, because they meet these requirements, in addition to preserving the operational security. This work aims to show the development of the implementation of moisture analyzers on line on car dumper in Vale's Ponta da Madeira terminal. The methodology used in the measurement of the moisture analyzer uses the principle of microwave transmission, which is the best technology available in the market for this purpose. Among the stages of implementation, which ranges from the acquisition of equipment to the evaluation of operational controls and adjustments, is shown the period of each step, problems encountered and the solutions adopted. In short, there is currently online moisture measurement in the discharge of this site and are under implementation analysis during loading of shipment for process control.

Keywords: Online analyzers; humidity; Measurement.

1 Química Industrial, Especialista em MBA em Engenharia de Produção, Técnica Especializada de Laboratório, Vale, São Luís, Maranhão, Brasil.

2 Administração, Supervisora de Laboratório, Vale, São Luís, Maranhão, Brasil.

3 Administração; Gerente de Área de Desenvolvimento, Otimização de Processos e Laboratórios da Vale; Carajás, Pará, Brasil.

4 Engenharia de Minas, Mestra em Engenharia, São Luís, Maranhão, Brasil.

* Contribuição técnica ao 44 Seminário de Redução de Minério de Ferro e Matérias-primas, $15^{\circ}$ Simpósio Brasileiro de Minério de Ferro e 2o Simpósio Brasileiro de Aglomeração de Minério de Ferro, 15 a 18 de setembro de 2014, Belo Horizonte, MG, Brasil. 


\section{INTRODUÇÃO}

Estudos revelam que o Brasil continua tendo a competitividade como um de seus aliados e diferenciais no mercado internacional e, portanto, possui o menor custo médio de produção de minério de ferro no mundo. Para as mineradoras conseguirem esta redução de custos foi necessário desenvolver uma série de ações com o objetivo de elevar a produtividade e otimizar os processos.

A Vale por ser a maior mineradora deste mercado no Brasil tem contribuição expressiva para estes resultados. No intuito de agregar valor aos seus produtos e tornar seu negócio sustentável, cada vez mais tem intensificado a estratégia de automatizar os processos em todas as áreas desde a administrativa até a área técnica.

Para valorar os produtos exportados pela Vale no Brasil, a mesma dispõe de um laboratório em cada site em que atua, a saber: Minas Gerais, Espírito Santo, Rio de Janeiro, Pará e Maranhão. No laboratório do Porto de Ponta da Madeira no Maranhão, para as análises de minério de ferro, são determinados os percentuais de ferro, sílica, manganês, fósforo, alumina e granulometria e umidade.

Diante deste contexto, a necessidade por resultados de análises laboratoriais dentro das indústrias são cada vez mais exigentes em termos de tempo de resposta e precisão. Aliado a isso, a elevação do volume de minério de ferro exportado e o aumento da variabilidade desses produtos requerem processos cada vez mais rigorosos e tomadas de decisões mais rápidas.

Os analisadores on-line têm um papel fundamental neste cenário, pois atendem tais exigências, além de preservarem a segurança operacional, porque retiram os profissionais da linha de fogo. Conforme destacou Kleber Terra (Diretor de Operações e Infraestrutura da Samarco) no $1^{\circ}$ Workshop de Analisadores on line na mineração, é fundamental que as informações das variáveis de processo sejam disponibilizadas em tempo real, o que já é uma realidade. Ressaltou ainda que o desafio é ampliar sua abrangência e utilização para absorver os benefícios que os analisadores on line podem gerar para o setor.

Neste sentido, este trabalho mostra o desenvolvimento da implantação de analisadores de umidade on line na descarga dos vagões da Vale no Terminal Ponta da Madeira. Esta implantação foi motivada pelo objetivo de identificar as variações de umidade do minério de ferro entre a expedição em Carajás no Pará e a descarga em São Luís no Maranhão, que possam interferir no processo. A determinação da umidade é uma variável que tem importância significativa no controle deste processo, pois sofre alterações de acordo com o índice pluviométrico devido à ocorrência de chuvas torrenciais no período chuvoso na cidade de São Luís, estado do Maranhão.

\section{MATERIAIS E MÉTODOS}

A metodologia utilizada na medição de umidade dos analisadores on line usa o princípio de transmissão de microondas, que é a melhor tecnologia disponível no mercado para este fim. As microondas são altamente sensíveis às moléculas de água. Ao penetrar na camada de material, causam a rotação das moléculas de água livre. Como resultado, a velocidade da microonda é reduzida (mudança de fase) e sua intensidade é diminuída (atenuação). A mudança de fase e a atenuação das microondas representam uma medição direta da umidade do material.

\footnotetext{
* Contribuição técnica ao 44 Seminário de Redução de Minério de Ferro e Matérias-primas, 15 Simpósio Brasileiro de Minério de Ferro e 2ํ Simpósio Brasileiro de Aglomeração de Minério de Ferro, 15 a 18 de setembro de 2014, Belo Horizonte, MG, Brasil.
} 
O analisador de umidade é composto por duas antenas (emissora e receptora), um suporte, um sensor de nível ultrasônico, conforme Figura 1:

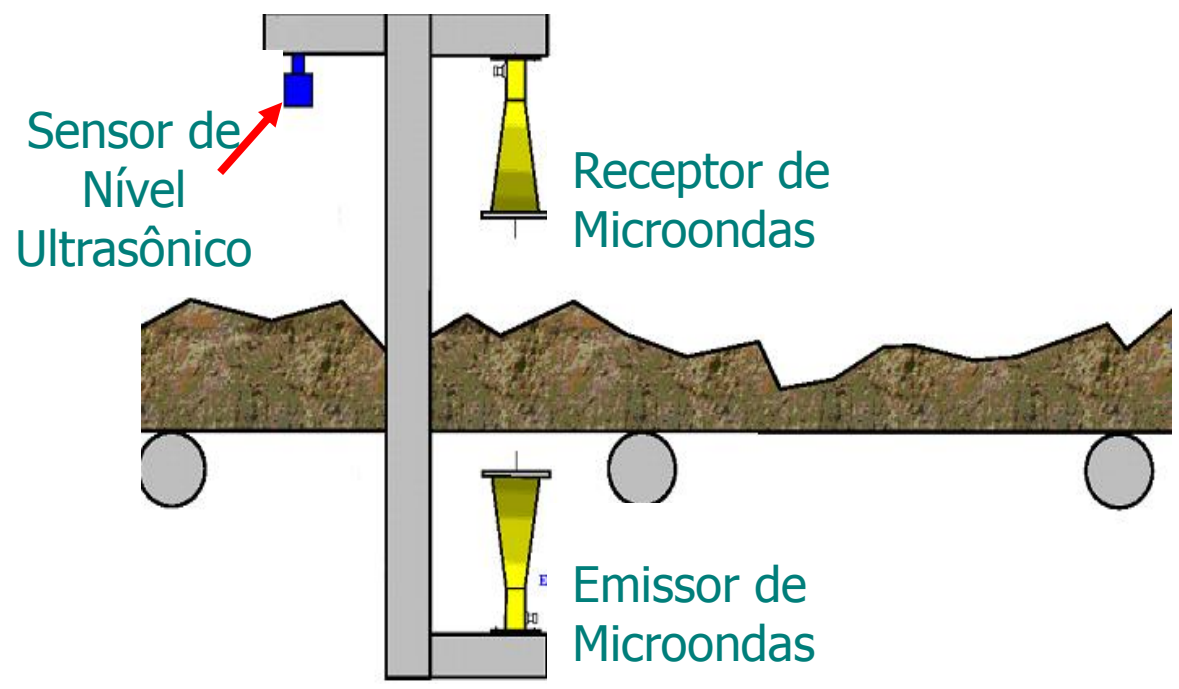

Figura 1. Analisador Umidade On Line.

As etapas de implantação abrangeram: aquisição dos equipamentos, montagem dos analisadores de umidade, instalação de energia e comunicação, implantação de proteção das antenas, calibração do analisador de referência, operação assistida, implantação, avaliação de controles e ajustes operacionais.

\section{RESULTADOS E DISCUSSÃO}

Este item mostra as etapas de implantação bem como o tempo gasto em cada etapa, conforme proposto na metodologia de acordo com a Tabela 1.

Tabela 1. Etapas de Implantação dos Analisadores de Umidade On Line

\begin{tabular}{|l|l|l|l|l|l|l|l|}
\hline \multicolumn{1}{|c|}{ Cronograma de Implantaç̃o dos Analisadores On Line em São Luis } \\
\hline \multicolumn{1}{|c|}{ Etapas } \\
\hline Aquisição de 04 analisadores
\end{tabular}

A aquisição dos analisadores passou pela análise de tecnologias disponíveis no mercado para determinação da umidade e o equipamento deveria ser robusto o suficiente para garantir baixa frequência de manutenção e elevada faixa de trabalho de umidade (7 a 20\%). As tecnologias encontradas foram medições por ondas

* Contribuição técnica ao 44 Seminário de Redução de Minério de Ferro e Matérias-primas, 15o Simpósio Brasileiro de Minério de Ferro e 2o Simpósio Brasileiro de Aglomeração de Minério de Ferro, 15 a 18 de setembro de 2014, Belo Horizonte, MG, Brasil. 
próximas ao infravermelho e ondas tipo microondas. O equipamento com princípio de funcionamento de microondas mostrou-se com maior vantagem.

A montagem dos equipamentos sobre as correias transportadoras durou 04 meses devido ao elevado working rate destes equipamentos. Após esta etapa percebeu-se a necessidade de criar um dispositivo para proteger as antenas dos analisadores. Deste modo, foram desenvolvidos dois dispositivos: o "balancim", que é composto por 2 rolos sob a correia, dispostos antes e após a antena emissora e tem a função de evitar que a correia entre em contato com a antena, evitando assim o seu desgaste; o "quebra-camelo", que é composto por uma placa que fica sobre a correia, disposto antes da antena receptora, no sentido do fluxo e tem a função de limitar o nível de material, evitando que o minério danifique a antena receptora.

É interessante destacar que, devido à dificuldade de coletar amostras para calibração nas correias transportadoras localizadas após os viradores de vagões, em função da baixa disponibilidade de parada, foi instalado um analisador num transportador da linha de amostragem, pois o laboratório tem mais autonomia de parada e assim a curva foi replicada aos demais. A calibração foi feita comparando os resultados com as umidades obtidas pelo método convencional de laboratório (secagem em estufa), conforme Norma ISO 3087. A Figura 2 mostra estes dados e os parâmetros de calibração utilizados como critérios de desempenho para aceitação dos equipamentos: precisão (desvio padrão de 0,24 ) e fator de correlação $(r=0,76)$.

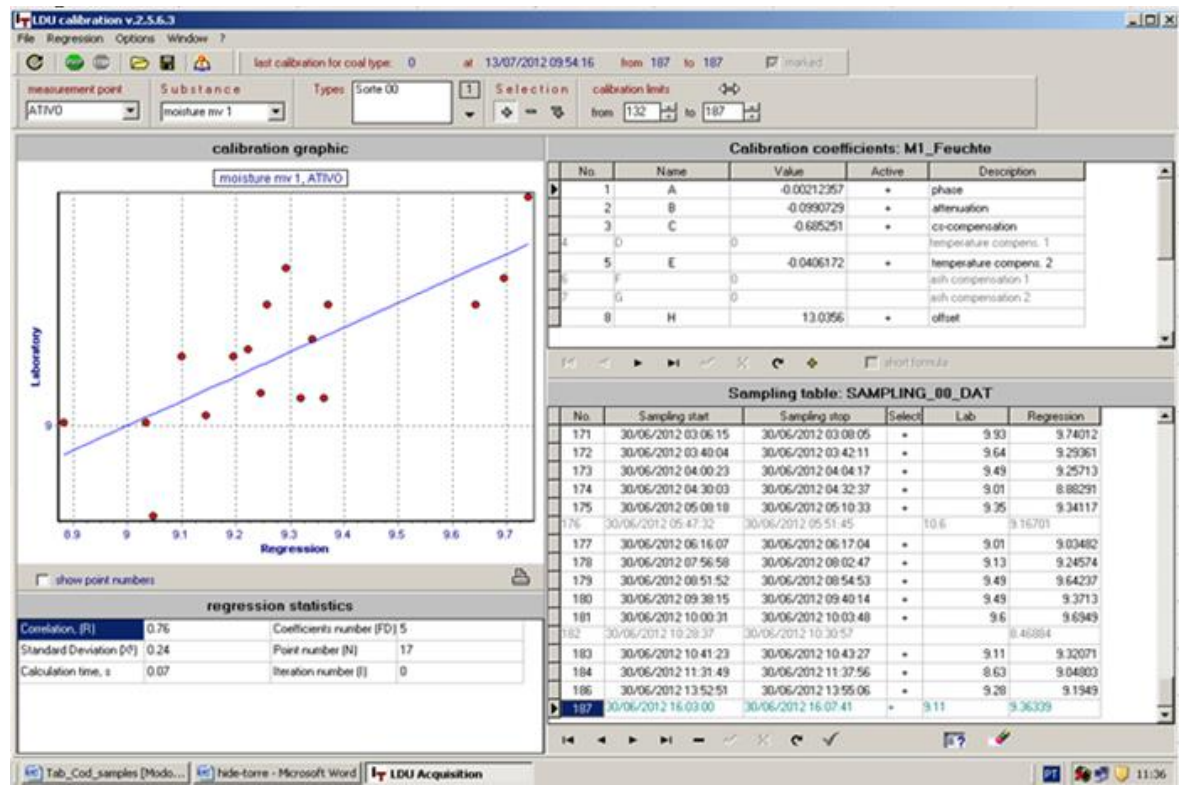

Figura 2. Dados de umidade usados para calibração

Por fim, com a implantação dos dados dos analisadores já comunicando com o sistema PIMS (Sistema de Gerenciamento de Informações de Processo), foi possível verificar as leituras de umidade e em seguida avaliar e adequar a curva para cada equipamento através da criação de controles automáticos. De acordo com o gráfico da Figura 3, pode-se verificar uma maior diferença entre a expedição e descarga em São Luís devido às relevantes alterações do índice pluviométrico. 


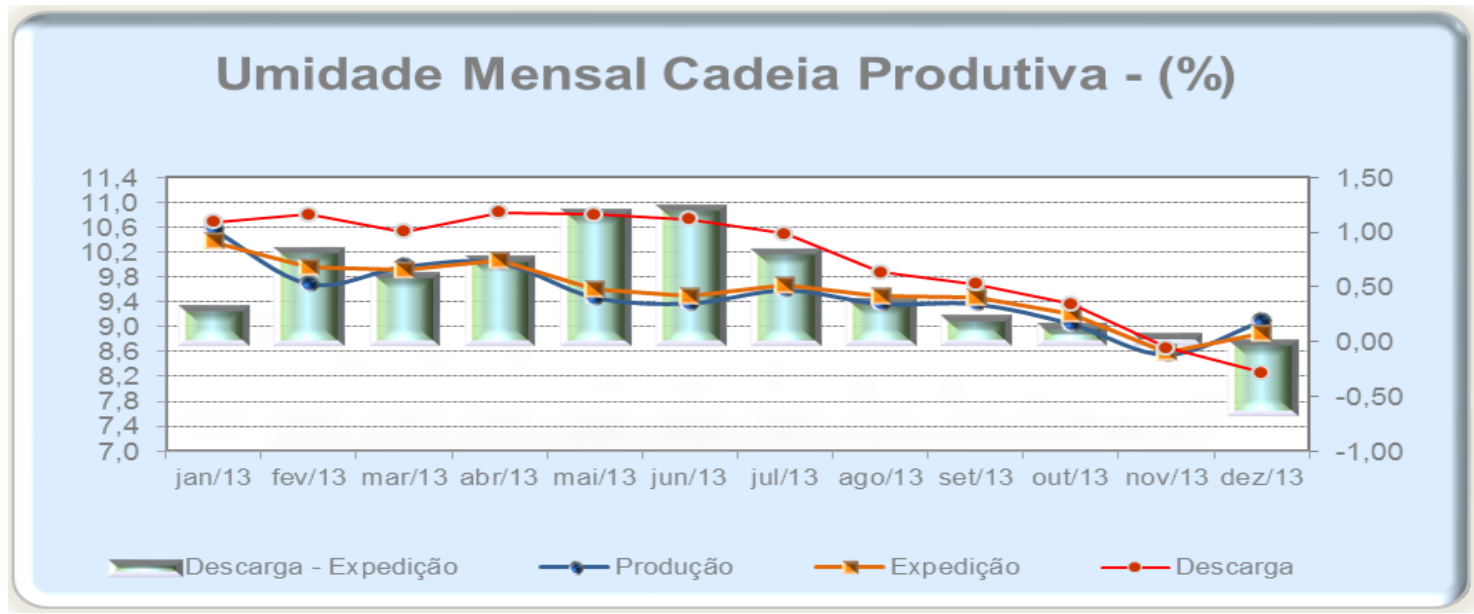

Figura 3. Umidade Mensal na Expedição e Descarga (Analisadores On line)

A principal vantagem da aquisição do equipamento com princípio de funcionamento tipo microondas é que apresenta a propriedade de penetrar todo o leito de minério sem sofrer grandes atenuações e, dessa forma, fornecer medidas representativas desde a superfície até a base do leito. No que se refere aos equipamentos tipo infravermelho, os mesmos analisam apenas a umidade retida na superfície do leito. Com relação à calibração é importante ressaltar que em São Luis, a mesma deve ser feita em dois tempos, no período chuvoso e seco, em decorrência da diferença relevante do índice pluviométrico.

\section{CONCLUSÃO}

Em suma, atualmente há medição de umidade on line na descarga dos viradores de vagões em São Luís, o que contribui para o monitoramento desta variável em toda a cadeia produtiva: produção, expedição e descarga. Com a identificação da umidade é possível definir melhores estratégias de empilhamento do minério que possam interferir no processo.

Os medidores de umidade se mostraram eficientes ao objetivo proposto que era realizar análises de umidade em tempo real e em ambientes agressivos, além de requerer menos intervenções de manutenções e calibrações. É importante que o monitoramento dos dados seja diário a fim de avaliar a acurácia e a necessidade de adequar a curva de calibração.

Atualmente, está em fase de implantação a análise de umidade on line durante o carregamento do embarque para controle de processo.

\section{Agradecimentos}

Agradecemos a Deus pela capacidade de superar as dificuldades e à administração da Vale, pela oportunidade de realizar este trabalho.

\section{BIBLIOGRAFIA}

1 Maria Bianchetti. Diário do Comércio. Estudo revela que o setor de mineração do Brasil é competitivo [acesso em 11 mai. 2014]. Disponível em:

http://diariodocomercio.com.br/noticia.php?tit=estudo_revela_que_o_setor_de_minerac ao_do_brasil_e_competitivo\&id=134944

* Contribuição técnica ao 44 Seminário de Redução de Minério de Ferro e Matérias-primas, 15ํ Simpósio Brasileiro de Minério de Ferro e $2^{\circ}$ Simpósio Brasileiro de Aglomeração de Minério de Ferro, 15 a 18 de setembro de 2014, Belo Horizonte, MG, Brasil. 
2 Gilberto DC. Relatório Técnico 06. Análise Comparativa da Competitividade do Setor Mineral Nacional. [acesso em 11 mai. 2014]. Disponível em:

http://simineral.org.br/arquivos/AnliseComparativadaCompetitividadedoSetorMineralNac ionalPlanoNacionaldeMinerao2030MME.pdf

3 Instituto Brasileiro de Mineração. Workshop Analisadores On Line na Mineração Reúne Especialistas em Vitória. [acesso em 11 mai. 2014]. Disponível em: http://www.ibram.org.br/150/15001005.asp?ttCD_CHAVE=30167

4 Organização Internacional de Padronização:ISO. Iron Ores - Determinação of moisture contente of a lot. [acesso em 14 mai.2014]. Disponível em:

http://www.iso.org/iso/catalogue_detail.htm?csnumber=21490

* Contribuição técnica ao $44^{\circ}$ Seminário de Redução de Minério de Ferro e Matérias-primas, 15ํ Simpósio Brasileiro de Minério de Ferro e $2^{\circ}$ Simpósio Brasileiro de Aglomeração de Minério de Ferro, 15 a 18 de setembro de 2014, Belo Horizonte, MG, Brasil. 